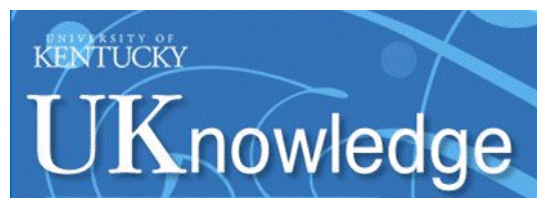

University of Kentucky

UKnowledge

Health Management and Policy Faculty

Publications

Health Management and Policy

8-2013

\title{
Geomapping Telehealth Access to Developmental-Behavioral Pediatrics
}

\author{
Neelkamal S. Soares \\ University of California - Los Angeles \\ Andrew O. Johnson \\ University of Kentucky \\ Nitish Patidar \\ University of Alabama - Birmingham
}

Follow this and additional works at: https://uknowledge.uky.edu/hsm_facpub

Part of the Health Services Administration Commons, and the Health Services Research Commons Right click to open a feedback form in a new tab to let us know how this document benefits you.

\section{Repository Citation}

Soares, Neelkamal S.; Johnson, Andrew 0.; and Patidar, Nitish, "Geomapping Telehealth Access to Developmental-Behavioral Pediatrics" (2013). Health Management and Policy Faculty Publications. 1. https://uknowledge.uky.edu/hsm_facpub/1

This Article is brought to you for free and open access by the Health Management and Policy at UKnowledge. It has been accepted for inclusion in Health Management and Policy Faculty Publications by an authorized administrator of UKnowledge. For more information, please contact UKnowledge@lsv.uky.edu. 


\section{Geomapping Telehealth Access to Developmental-Behavioral Pediatrics}

\section{Digital Object Identifier (DOI)}

http://dx.doi.org/10.1089/tmj.2012.0226

\section{Notes/Citation Information}

Published in Telemedicine and e-Health, v. 19, no. 4, p. 585-590.

This is a copy of an article published in the Telemedicine and e-Health (c), 2013, copyright Mary Ann Liebert, Inc.; Telemedicine and e-Health is available online at: http://online.liebertpub.com. 


\section{Geomapping Telehealth Access to Developmental-Behavioral Pediatrics}

\author{
Neelkamal S. Soares, $M D_{,}{ }^{1}$ Andrew O. Johnson, $P h D_{1}{ }^{2}$ \\ and Nitish Patidar, MBBS, $M H A^{3}$ \\ ${ }^{1}$ Department of Pediatrics, David Geffen School of Medicine, \\ University of California Los Angeles, Los Angeles, California. \\ ${ }^{2}$ Department of Health Services Management, University \\ of Kentucky College of Public Health, Lexington, Kentucky. \\ ${ }^{3}$ Health Services Administration, University of Alabama \\ at Birmingham, Birmingham, Alabama.
}

\begin{abstract}
Background: Geographic information systems (GIS) mapping is fairly novel in describing utilization of health services. Our study is the first to use GIS to demonstrate that telehealth pediatric specialty service access would create substantial savings in travel time and distance compared with accessing a tertiary-care center for similar service. Materials and Methods: A retrospective chart review of telehealth encounters and geocoding of patients' address were done with actual travel along road calculations to estimate travel time and distance for a visit, compared with a hypothetical visit to the nearest tertiary-care site for the similar service. Results: Over a 2-year period, 255 telehealth visits by 171 patients with a variety of developmental and behavioral diagnoses were made to five telehealth sites. The median travel time and distance saved by accessing a telehealth site were $66.9 \mathrm{~min}$ and 63.8 miles, respectively. Of these patients, $12.3 \%$ had a median negative estimated savings of 52.7 min and 39.0 miles, which was associated with longer travel burden. Using the straight-line method underestimated the total time and distance traveled by approximately one-quarter of the actual distance (median distance of 20.5 miles underestimate relative to the median distance of 100.7 miles). Conclusions: Telehealth patients experienced significant reduction in travel times and distances. Patients/families would accept an increased burden of spatial accessibility in exchange for reduced burdens in other aspects of access, such as accommodation or acceptability when engaging telehealth services. Using a road network-based method is more accurate than previously used straight-line methods in calculating distance impedance.
\end{abstract}

Key words: telehealth, telemedicine, business administration/ economics

\section{Introduction}

J.M., a 10-year-old boy with developmental delay and a genetic disorder, was getting into trouble at school for inappropriate and disruptive behaviors. He was at risk of being suspended and placed in an inpatient facility. The family was at their wits' end, and the local mental health agencies in eastern Kentucky were unable to provide specific guidance on resolving the situation. The family had transportation difficulties, and J.M. was reported to do poorly with transitions and long travel. The family sought out the first author's (N.S.) telemedicine (TM) clinic at their nearby facility (only 20 miles from their home), compared with visiting the tertiary-care center (120 miles away). His care involved multiple visits, over a period of almost 3 years, both for parent advocacy and training and for medication adjustments. As a result, J.M. has been able to continue in his school environment with increased behavioral supports. His guardian G.C. professed she would never have been able to achieve these outcomes had the TM site not existed. In her own words:

It is a big help with the shorter travel time and closer to home that I can do this by myself. If the visits were in Lexington, my husband would have to travel with me, and this is difficult with him working a full time job. Another is that my child arrives less agitated due to the shorter time confined in the car.

Telehealth has long been recognized as a method to reduce barriers to access in terms of geographic distances and time spent on travel. ${ }^{1,2}$ Kentucky adopted telehealth in the 1990s, and today the Kentucky TeleHealth Network ${ }^{3}$ connects over 200 healthcare facilities, community mental health centers, public school clinics, and prison clinics via direct, point-to-point communication circuits or via highspeed Internet connectivity.

Developmental-behavioral pediatrics (DBP) is a subspecialty of pediatrics involving evaluation and management of childhood and adolescent developmental and behavioral problems. For families from eastern Appalachian Kentucky, accessing a DBP specialist often entails travel of up to 200 miles each way to the nearest tertiary-care center at the University of Kentucky (UK) in Lexington. In 2008, UK DBP services extended through Kentucky TeleHealth Network to five eastern Kentucky health facilities: St. Claire Regional Medical Center in Morehead (and its sub-network locations at Sandy Hook and Olive Hill), North Fork Valley Community Health Center in Hazard, and Highlands Regional Medical Center in Prestonsburg. All locations lie in the heart of Appalachian Kentucky (Fig. 1).

Access to healthcare services has traditionally been defined as the ability to meet the need or demand of healthcare services. ${ }^{4} \mathrm{~A}$ commonly encountered theoretical framework of access is the "Five As of Access": Availability (geographic/physical), Accessibility, Accommodation, Affordability, and Acceptability. ${ }^{5}$ The most commonly used 


\section{SOARES ET AL.}

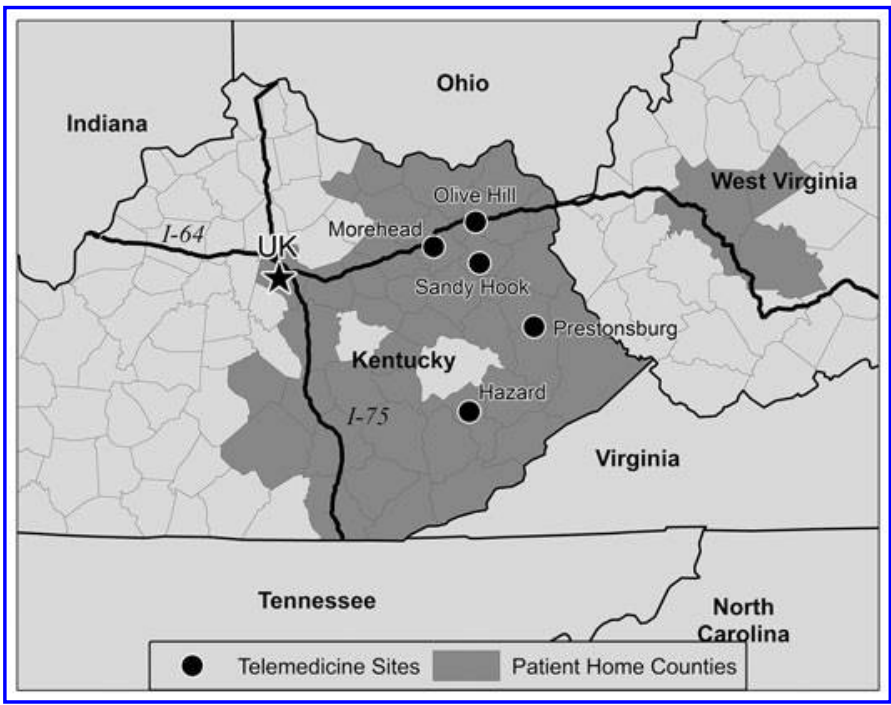

Fig. 1. Site locations and patient counties.

metric for geographic accessibility is some form of travel-based impedance, typically a distance, time, or travel cost. ${ }^{6}$ Distance between any two points may be calculated as a straight line or as the sum of road lengths traveled along a road network connecting the two points. As a result, the estimation of starting and ending points of travel routes can vary in their accuracy and precision.

Geocoding is the systematic assignment of spatial coordinates to data based on address information and is a key feature of geographic accessibility studies. Geographic information system (GIS) technology integrates hardware, software, and data for capturing, managing, analyzing, and displaying forms of geographically referenced information. ${ }^{7}$ GIS is used in healthcare to understand, investigate, and improve need assessment, health service availability, and healthcare utilization patterns using various geographic, visual, and spatial analytic techniques. ${ }^{8}$ Travel distance, time, and transit costs have great impact on patient access to healthcare. ${ }^{9,10}$ GIS-based estimation techniques can directly incorporate these aspects as part of a methodological investigation of access to care. ${ }^{7,11}$ Although several studies have used GIS-based techniques to examine accessibility, fewer have examined actual utilization of services. ${ }^{12}$ GIS-enabled research studies in pediatric populations ${ }^{13,14}$ have used "straight-line" calculation for distance. There have also been studies using GIS with telehealth to assess locational efficiency of adult subspecialist distribution, ${ }^{15}$ but no studies to describe program utilization of telehealth services for a pediatric subspecialty such as DBP.

We undertook this study to describe the utilization of DBP subspecialty services delivered by telehealth across Eastern Kentucky. We hypothesized that access to telehealth sites would create substantial savings in travel time and distance compared with travel to the hub tertiary-care center for similar service. We also hypothesized that the method of using actual travel along a road network with GIS is more accurate than using traditional straight-line calculation methods.

\section{Materials and Methods}

Following approval by the UK Office of Research Integrity, the study involved a retrospective review of all patients seen by author N.S. at the telehealth sites over a 2-year period from January 2009 to December 2010. Billing capture data yielded telehealth encounters and provided a de-identified dataset including gender, age, insurance provider, International Classification of Diseases, 9th edition (ICD-9) diagnoses codes, patient address, and the telehealth site where the encounter occurred. The addresses of patient and telehealth site were geocoded, and all data are reported in groups or aggregate.

Address geocoding was carried out using ArcGIS Online North American Geocoding Service version 10. ${ }^{16}$ Models were executed with the ArcGIS Network Analyst extension in ArcGIS version 10, with ESRI's Streetmap North America data serving as the network layer. These models estimated the travel time and distance from the patient's home address to the telehealth site actually visited and also from their home to the tertiary clinic site at the UK in Lexington (hereafter referred to as the UK site). Descriptive statistics, graphs, and cross-tabulations were created by both patient and visit counts as seen at each location by age ranges, gender, diagnoses groups, and insurance coverage and were performed using the JMP version 9 statistical package. ${ }^{17}$

\section{Results}

In total, 255 telehealth visits made by 171 unique patients were recorded between January 2009 and December 2010. Visit counts per unique telehealth patient ranged from one to eight. Eight visits were made by four patients living in three counties of West Virginia, and 247 visits were made by 167 patients from 40 Kentucky counties. The mean patient age as of encounter date was 6.6 years of age (standard deviation, 3.12 years). The distribution of patients and their associated visits by gender, telehealth site visited, insurance coverage, and diagnosis group can be found in Table 1 .

Of the 171 patients in the study sample, the majority were male (82\%), visited the Hazard telehealth site (40\%), and had a primary diagnosis of developmental delay (27\%). In the diagnosis description section of Table 1 , the "Other" category consists of 13 primary diagnoses across 30 patients, with the most frequent being oppositional defiant disorder $(n=8)$, anxiety disorder $(n=5)$, and chromosomal anomaly $(n=5)$.

Figure 2 shows the relative distributions of the calculated travel times and distances for each of the 255 visits. Two travel routes are calculated here, along with the travel distance/time saved by accessing telehealth site. The first travel route was calculated from the patient's home address to the UK site, which would be the distance traveled in the absence of the telehealth sites. The second was calculated from the patient's home address to the actual telehealth location he or she visited. Finally, we calculate the time/distance saved by each telehealth visit as the difference between the former two estimates. The dashed line indicates zero as a reference point in all of the charts below. As the frequency distributions of both the time and distance measures described here are all generally skewed, we report 
Table 1. Descriptive Statistics

COUNT (\%) BY INDIVIDUAL

PATIENTS $\quad$ VISITS

$(N=171) \quad(N=255)$

\begin{tabular}{l|r|r}
\multicolumn{3}{l|}{ Gender } \\
\hline Male & $142(83.0)$ & $217(85.1)$ \\
\hline Female & $29(17.0)$ & $38(14.9)$ \\
\hline
\end{tabular}

\begin{tabular}{l|c|c}
\hline \multicolumn{3}{l|}{ Site visited } \\
\hline Hazard & $69(40.4)$ & $88(34.5)$ \\
\hline Morehead & $53(31.0)$ & $87(34.1)$ \\
\hline Prestonsburg & $27(15.8)$ & $47(18.4)$ \\
\hline Olive Hill & $13(7.6)$ & $22(8.6)$ \\
\hline Sandy Hook & $9(5.3)$ & $11(4.3)$ \\
\hline
\end{tabular}

\begin{tabular}{l|c|c}
\hline \multicolumn{3}{l}{ Diagnosis } \\
\hline Developmental delays & $45(26.3)$ & $66(25.9)$ \\
\hline Autism & $35(20.5)$ & $65(25.5)$ \\
\hline ADHD & $31(18.1)$ & $54(21.2)$ \\
\hline Language/learning issues & $16(9.4)$ & $16(6.3)$ \\
\hline Behavior disorder & $14(8.2)$ & $16(6.2)$ \\
\hline Other & $30(17.5)$ & $38(14.9)$ \\
\hline Insurance type & $133(77.8)$ & $201(78.8)$ \\
\hline Medicaid & $37(21.6)$ & $53(20.8)$ \\
\hline Private & $1(0.6)$ & $1(0.4)$ \\
\hline Missing &
\end{tabular}

$A D H D$, attention deficit hyperactivity disorder. the median and interquartile range as measures of central tendency and variation, respectively.

As seen in Figure 2, the median travel time to the accessed telehealth site is roughly half the distance to the UK site. The median distance to the accessed telehealth site is approximately 37\% of the distance to the UK site. The median travel time and distance saved by accessing a telehealth site were $66.9 \mathrm{~min}$ and 63.8 miles, respectively. Note the few instances where the time and distance saved are negative; these correspond to patients electing to access a TM site that is further away (in time and distance) than the UK site. Of the 255 visits on record, in total, 25 visits (made by 21 of the 171 total patients) had a negative estimated time savings, including one patient making five visits. These negative time savings ranged from $-0.3 \mathrm{~min}$ to $-153.1 \mathrm{~min}$, with a median of $-52.7 \mathrm{~min}$, and an associated median travel distance savings of -39.0 miles. For this subgroup of patients, the mean patient age was 7.5 years, $81.0 \%$ were male, $76.2 \%$ visited the Morehead TM site, and 66.7\% were Medicaid-insured. The most common diagnoses in this subgroup were autism (28.6\%) and developmental delays (23.8\%). They lived a median distance of 48.4 miles from the UK site and 77.1 miles away from their visited TM site.

The travel time and distance savings grouped by TM site appear in Figure 3. The median time saved ranges from a low of $37 \mathrm{~min}$ for the Morehead location to a high of $134 \mathrm{~min}$ for the Prestonsburg location. A similar pattern is found in the median distance savings by site, with a low of 36 miles to a high of 111 miles. Note that those facilities with the largest travel time/distance to site outliers in Figure 2 are the same sites that have several visits reflecting negative time/distance saved (Hazard and Morehead).

As previously noted, 25 patient visits had a negative time/distance savings when traveling to their visited TM site. All of these 25 visits were made to either the Morehead or Hazard location and composed $14.3 \%$ of the total 175 visits to these sites during the study period. The distribution of these visits by gender, telehealth site visited, insurance coverage, and diagnosis group can be found in Table 2 .

Figure 4 compares the distribution of total distance traveled to their TM site between visits with positive time/ distance savings to the TM site versus those with negative time/distance savings. As with Table 2, Figure 4 only includes visits made to the Morehead and Hazard sites. The median distance driven to the TM site by the negative distance savers was 71.17 miles versus 41.25 miles for the positive distance savers.

Figure 5 illustrates how estimates of travel distance using a straight-line, point-to-point method can yield biased estimates compared with the more valid measurements acquired from calculating distance along a road

network. Figure 5 is a histogram of the

\begin{tabular}{l}
$100.66 / 44.03$ \\
$37.70 / 35.75$ \\
$63.81 / 65.22$ \\
\hline
\end{tabular}

$63.81 / 65.22$
Fig. 2. Times/distances: home to main site at the University of Kentucky (UK), home to tele-

medicine (TM), and savings. IQR, interquartile range.

$53.24 / 52.52$

$66.86 / 83.65$

Home to TM site

Time Saved

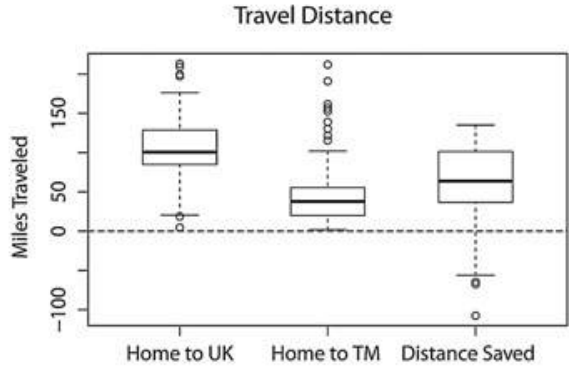




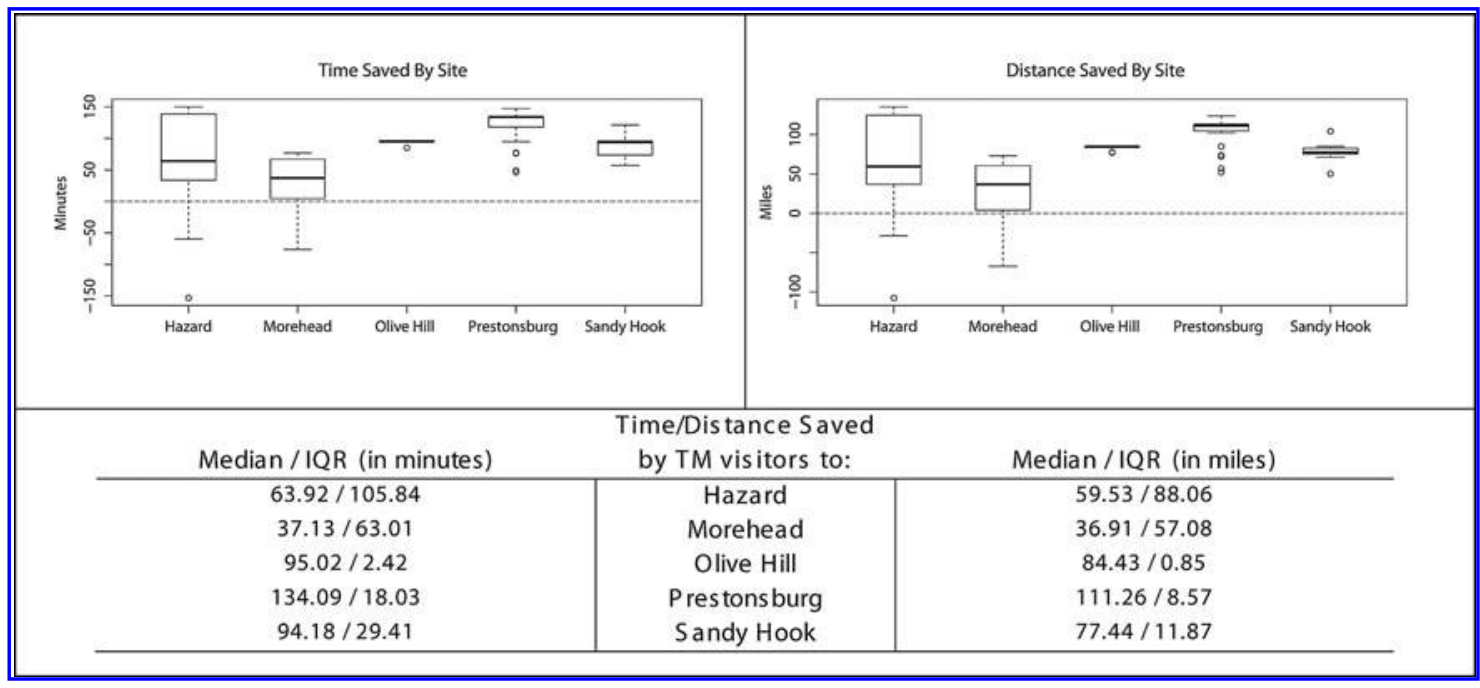

Fig. 3. Travel time/distance savings by telemedicine (TM) site location. IQR, interquartile range. difference between the straight-line and road network-based travel estimates to the UK site for each patient visit in our sample.

The straightline method underestimates the true travel distance between the UK site and the patient's home by a median distance of 20.5 miles (using the road network method as the true standard of distance). These underestimates range from a minimum of 0.3 miles to a maximum of 60.6 miles. In our study, we found that using the straight-line method underestimated the total time and distance traveled to the UK site by approximately one-quarter of the actual distance, with a median distance of 20.5 miles underestimate relative of the median distance of 100.7 miles.

\section{Discussion}

GIS is a fairly novel method to describe healthcare utilization, and, to our knowledge, this is the first time that GIS mapping techniques have been used to describe utilization of a pediatric specialty outpatient service. DBP continues to experience provider shortages, and there are increasing numbers of children with developmental and behavioral issues encountered by primary care clinicians. Although TM may not provide a solution to the manpower shortage, it may alleviate the geographic access barriers. At present, there are few DBP clinicians in the United States using telehealth, and we hope that more embrace telehealth to complement their existing models of healthcare

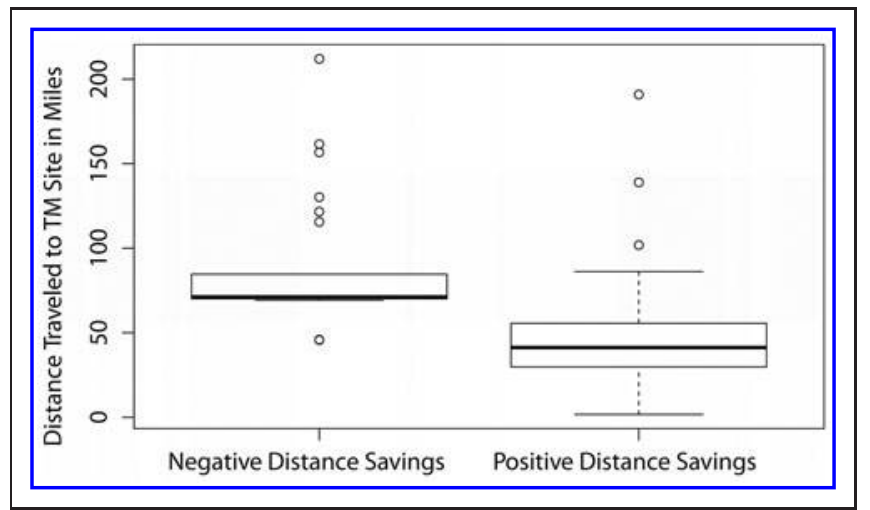

Fig. 4. Distance to telemedicine (TM) site by distance savings group. 


\section{GEOMAPPING ACCESS TO PEDIATRIC SERVICE}

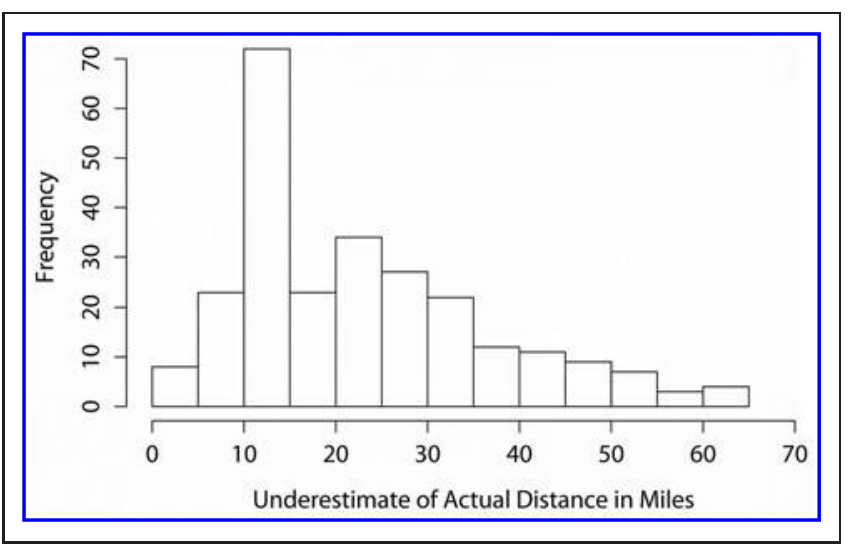

Fig. 5. Straight-line distance errors.

delivery. However, it is critical that DBP clinicians intending to pursue telehealth modalities familiarize themselves with local regulatory issues and community partners interested in partnerships. ${ }^{18}$

As expected, there were substantial travel savings per visit for families accessing the telehealth site versus the tertiary-care center. In this article, we have chosen not to elaborate on fiscal savings, as that takes into account indirect costs beyond travel savings, and we will present those data in a separate manuscript including system costs of telehealth. We believe that our study provides a more accurate description of utilization of health services by seeking to geocode actual patient addresses on which to base calculations. Although this is a slightly more laborious process than straight-line estimation method, it does seek to be more accurate compared with previous attempts to use centroid of a zip-code of patient location ${ }^{19}$ or to use the distance between the telehealth site and tertiary-care center as a proxy. ${ }^{20}$ To calculate distance along a road network, a user would need software that can select the shortest route between two sites based on available road network data and then aggregate the distances of the road components composing the selected path. Modern GIS software packages have automated this process, and road network data are available from a variety of commercial and noncommercial sources, making the continued use of straight-line distance calculations decreasingly defensible in terms of measurement validity.

The geocoded location of a patient address is considered protected health information, and protecting patient anonymity is a foremost consideration in public reporting of spatially referenced patient data. Some studies have sought to involve geomasking, which seeks to conceal patient or event locations through aggregation or the intentional introduction of "jitter" into the location's coordinates. ${ }^{21}$ Additionally, geomasking leads to trade-off between the accuracy of spatial information and protecting health information. ${ }^{22,23}$ As we do not show any maps of individual patient's point locations, we did not need to use geomasking. Furthermore, our reported tabulations are all presented in aggregate with no potential to identify individual patients.

The method of determining travel time used here does not take into consideration any delay due to traffic, weather, or other similar random impediments to travel that may occur. Generally, the longer the road segment or total trip distance, the less the impact of these types of travel barriers. ${ }^{15}$ These travel impediments would be expected to have greatest influence in urban areas; however, our calculations were for a mostly rural area. The method we used is able to account for certain functional characteristics of roadways in the preliminary shortest-path selection process: enforcing direction on one-way roads, avoiding toll roads, allowing U-turns, accounting for speed limits in time calculations, etc.

An interesting finding of this study is the number of patients who had negative savings of time and distance in accessing the telehealth site, as they drove further to access telehealth than it would have taken to drive to the main/tertiary clinic site. This can be conceptualized as an exchanging of different barriers to access. Using the " 5 As" paradigm of access, ${ }^{5}$ we propose that this set of negative distance-saving travelers were willing to accept an increased burden of spatial accessibility (as an increase in travel time/distance) in exchange for reduced burdens in other aspects of access, such as accommodation or acceptability. For instance, the average waiting list lead time for new telehealth appointments (for the first author N.S.) was 4 weeks, whereas the same waiting list lead time at the tertiary clinic site was 9 weeks. If a patient's family accepted an increased distance burden by electing to travel longer distances (a spatial accessibility barrier), they could reduce their waitlist lead time (an accommodation barrier) by accessing the same clinician via telehealth. Alternatively, patients' families may have felt more comfortable accessing the telehealth sites in rural or micropolitan settings (an acceptability barrier), as opposed to traveling a shorter distance to visit the tertiary-care site in an urban environment. It is also worth noting that longer total travel distances were associated with negative travel distance savings to the two TM sites servicing negative distance-saving patients. We theorize that as the total trip distance increases, the marginal impact of negative distance savings may be reduced. Alternatively, this may simply result from some attractive feature of the chosen TM site's location that motivates patients to travel the longer distance to that site.

There are some limitations of this study. First of all, no independent verification was made of the diagnoses codes of the subject population; these were obtained from billing documentation by the study team. Additionally, we did not look at health outcomes of the telehealth patient population. It is possible that the population accessing the telehealth sites in some way differs from patients seen at the tertiary-care site. Also, we are unable to determine if the population who accessed the telehealth site is representative of the population of the counties from which they hail. We also did not look at patient comfort and satisfaction with TM, but these topics have been extensively covered elsewhere. ${ }^{24}$ Additionally, as anecdotally referenced by caregiver G.C. in the patient testimonial, it is anticipated that children with developmental and behavioral pediatric problems do poorly with long travel and transition, but this has not been systematically measured in studies comparing telehealth with inperson encounters. An argument can be made that repeat visits (as seen in 43 of 171 unique patients) are a proxy for satisfaction, 


\section{SOARES ET AL.}

although we cannot tell from the data how many chose to come to the tertiary-care site after one visit at the telehealth site.

Lastly, while the option to access telehealth sites belongs with patients and families, there are certain types of patients for whom telehealth evaluation is not ideal ${ }^{18}$ because the modality inherently has limitations (physical exam in particular). We did not see (as part of outcomes of evaluation) which patients were deemed necessary for inperson follow-up to complete diagnostics after a telehealth evaluation.

\section{Conclusions}

Using the novel methodology of GIS mapping to describe utilization of DBP specialty services in Kentucky, we determined that patients/ families were able to save considerable time and distance in access services through telehealth compared with similar services at a tertiarycare center. Using travel along a road network is more accurate in calculating distance by previous straight-line methods, and some patients are willing to accept increased travel burden to reduce other barriers such as accommodation or acceptability when accessing tertiary-care specialty pediatric services. As systems of healthcare continue to explore efficiency and family-centered approaches to service delivery, using methods like GIS mapping will be valuable to quantify, to some degree, patient- and family-related burden in accessing care. We believe that the methodology described in this article can be used by other disciplines of healthcare and service delivery models, whether rural or urban, specialty or primary care, telehealth or brickand-mortar settings. This information could be used to demonstrate the ability of models like telehealth to reduce access barriers and appear feasible to patients and their families. The finding that some families are willing to incur a "negative" burden of impedance is noteworthy for administrators and clinicians who plan on expanding services to novel geographic areas and may aid in service-planning decision making.

\section{Disclosure Statement}

No competing financial interests exist.

\section{REFERENCES}

1. Bashshur R. Telemedicine effects: Cost, quality, and access. J Med Systems 1995;19:81-91.

2. Ryan $V$, Stathis $S$, Smith $A$, Best $D$, Wootton R. Telemedicine for rural and remote child and youth mental health services. $J$ Telemed Telecare 2005;11(Suppl 2):76-78.

3. Kentucky TeleHealth Network. Available at www.mc.uky.edu/kytelecare/ (last accessed June 5, 2012).

4. Aday LA, Andersen RM. Equity of access to medical care: A conceptual and empirical overview. Med Care 1981;19(12):4-27.

5. Penchansky R, Thomas JW. The concept of access: Definition and relationship to consumer satisfaction. Med Care 1981;19:127-140.

6. Cromley E, McLafferty S. GIS and public health. New York: Guilford Press, 2012.

7. ESRI. What is GIS? Available at http://edcommunity.esri.com/aboutGIS/ whatisGIS.cfm (last accessed June 7, 2012).

8. McLafferty SL. GIS and health care. Annu Rev Public Health 2003;24:25-42.
9. Fortney J, Rost K, Zhang M, Warren J. The impact of geographic accessibility on the intensity and quality of depression treatment. Med Care 1999;37:884-893.

10. Perry B, Gesler W. Physical access to primary health care in Andean Bolivia. Soc Sci Med 2000;50:1177-1188.

11. Martin D, Wrigley $H$, Barnett $S$, Roderick P. Increasing the sophistication of access measurement in a rural healthcare study. Health Place 2002; 8:3-13.

12. Higgs G. A literature review of the use of GIS-based measures of access to health care services. Health Serv Outcomes Res Methodol 2004;5:119-139.

13. Feikin DR, Nguyen LM, Adazu K, Ombok M, Audi A, Slutsker L, Lindblade KA. The impact of distance of residence from a peripheral health facility on pediatric health utilisation in rural western Kenya. Trop Med Int Health 2009;14:54-61.

14. Acosta CD, Kit Delgado M, Gisondi MA, Raghunathan A, D'Souza PA, Gilbert G, et al. Characteristics of pediatric trauma transfers to a level I trauma center: Implications for developing a regionalized pediatric trauma system in California. Acad Emerg Med 2010;17:1364-1373.

15. Shannon GW, Buker CM. Determining accessibility to dermatologists and teledermatology locations in Kentucky: Demonstration of an innovative geographic information systems approach. Telemed J E Health 2010;16:670-677.

16. ESRI. ArcGIS. Available at http://store.esri.com/esri/ (last accessed June 13, 2012).

17. SAS Institute. JMP 9.0.3. Cary, NC: SAS Institute, 2012.

18. Soares NS, Langkamp DL. Telehealth in developmental-behavioral pediatrics. J Dev Behav Pediatr 2012;33:656-665.

19. Holmes JA, Carpenter WR, Wu Y, Hendrix LH, Peacock S, Massing M, et al. Impact of distance to a urologist on early diagnosis of prostate cancer among black and white patients. J Urol 2012;187:883-888.

20. Harper DC. Telemedicine for children with disabilities. Childrens Health Care 2006;35:11-27

21. Hampton KH, Fitch MK, Allshouse WB, Doherty IA, Gesink DC, Leone PA, et al. Mapping health data: Improved privacy protection with donut method geomasking. Am J Epidemiol 2010;172:1062-1069.

22. Olson KL, Grannis SJ, Mandl KD. Privacy protection versus cluster detection in spatial epidemiology. Am J Public Health 2006;96:2002-2008.

23. Kwan MP, Casas I, Schmitz BC. Protection of geoprivacy and accuracy of spatial information: How effective are geographical masks? Cartographica 2004;39:15-28.

24. Williams TL, May CR, Esmail A. Limitations of patient satisfaction studies in telehealthcare: A systematic review of the literature. Telemed J E Health $2001 ; 7: 293-316$.

Address correspondence to:

Neelkamal S. Soares, MD

Department of Pediatrics

David Geffen School of Medicine

University of California Los Angeles

300 UCLA Medical Plaza, Suite 3300

Los Angeles, CA 90095

E-mail: nsoares@mednet.ucla.edu

Received: September 4, 2012

Revised: November 15, 2012

Accepted: November 20, 2012 